\title{
The return trip effect: Why the return trip often seems to take less time
}

\author{
Niels van de Ven • Leon van Rijswijk • Michael M. Roy
}

Published online: 23 August 2011

(C) The Author(s) 2011. This article is published with open access at Springerlink.com

\begin{abstract}
Three studies confirm the existence of the return trip effect: The return trip often seems shorter than the initial trip, even though the distance traveled and the actual time spent traveling are identical. A pretest shows that people indeed experience a return trip effect regularly, and the effect was found on a bus trip (Study 1), a bicycle trip (Study 2), and when participants watched a video of someone else traveling (Study 3). The return trip effect also existed when another, equidistant route was taken on the return trip, showing that it is not familiarity with the route that causes this effect. Rather, it seems that a violation of expectations causes this effect.
\end{abstract}

Keywords Time perception · Return trip effect · Judgment and decision making

When we return from a conference, the return trip often seems shorter than the initial trip. This is odd, since the distance traveled and the actual time spent traveling are usually identical. Here, we investigated the existence of a return trip effect and explored two possible causes of this phenomenon. If a return trip effect exists, one possible cause might be an increase in familiarity and predictability. Previous research has shown that novel tasks are often

N. van de Ven $(\bowtie)$

Social Psychology \& TIBER, Tilburg University, PO Box 90153, 5000LE Tilburg, Netherlands

e-mail: n.v.d.ven@tilburguniversity.edu

M. M. Roy

Elizabethtown College,

Elizabethtown, PA, USA

L. van Rijswijk

Eindhoven University of Technology,

PO Box 90153, 5000LE Tilburg, Netherlands remembered as taking longer than they actually do, while familiar tasks are remembered as taking less time (AvniBabad \& Ritov, 2003; Boltz, Kupperman, \& Dunne, 1998; Hinds, 1999; Roy \& Christenfeld, 2007). Similarly, tasks that are unpredictable are remembered as taking longer than similar coherent or predictable tasks (Boltz, 1993, 1995, 1998). The unpredictability of the initial leg of the trip may make it so that it is remembered as being overly long. Conversely, the return trip is remembered as being short because it is now more familiar and predictable.

Alternatively, the return trip effect could be due to a violation of expectations. People often predict that tasks will take less time than they actually do (Buehler, Griffin, \& Ross, 2002; Kahneman \& Tversky, 1979; Roy, Christenfeld, $\&$ McKenzie, 2005). In general, people are fairly inaccurate when estimating how long things either have taken in the past (Block \& Zakay, 1997; Burt \& Kemp, 1991; Poynter, 1989; Wallace \& Rabin, 1960) or will take in the future (Buehler et al. 2002; Roy, Christenfeld \& McKenzie 2005). It may be that people have an expectation for a trip that is overly short, leading to a violation of this expectation when they take the trip. Hence, the initial trip takes longer than expected. For the return trip, the expectation is likely to be based on the experience of the (disappointingly long) initial trip. This leads to an upward adjustment in expectations for the return trip that is, happily, unmet. The return trip, therefore, feels shorter than the initial trip. Here, we try to establish whether or not there is a return trip effect and whether this might be due to a shift in familiarity or expectation.

Before the studies were undertaken, a pretest was conducted to test whether people actually experience this phenomenon in their daily life. Fifty-six students (43 females, $M_{\text {age }}=19$ years) indicated whether they "sometimes feel that the return trip seems shorter than the initial trip" and whether they sometimes feel that it seems longer, on scales from 1 (never) to 7 (always). In comparison with the initial trip, participants more often reported that the 
return trip felt shorter $(M=5.23, \mathrm{SD}=1.36)$ than that it felt longer $(M=3.59, \mathrm{SD}=1.80)$, paired-sample $t(55)=$ $4.21, p<.001, r^{2}=.24$. When given a forced choice about whether the initial trip or the return trip tended to feel shorter, participants were almost 3 times as likely to indicate that the return trip tended to feel shorter ( $73 \%$ chose the return trip vs. $27 \%$ for the initial trip). Similar to our own experiences, participants felt that a return trip effect occurs frequently. The return trip effect was further examined in a field study (Study 1), a field experiment (Study 2), and a controlled lab experiment (Study 3).

\section{Study 1}

In Study 1, the return trip effect was tested in a real-world situation, and possible explanations for the phenomenon were explored. Sixty-nine participants $\left(57\right.$ females, $M_{\text {age }}=$ 33 years) who had just returned from a day trip by bus from either a housekeeping fair (a large event where people received free goods related to housekeeping) or the Efteling (a large theme park) indicated which part of the trip felt longer. We took care to include only participants for whom the initial and return trips actually took the same time (which varied between 25 and $120 \mathrm{~min})^{1}$ and who were awake during both trips. After the return trip ended, the participants indicated how long they felt that the return trip had taken, as compared with the initial trip, on an 11-point scale from -5 (a lot shorter) to +5 (a lot longer). Participants exhibited a return trip effect, with the return trip feeling like it took less time than the initial trip $(M=-0.55, \mathrm{SD}=2.16$, with an average response significantly lower than 0$), t(68)=$ $2.12, p=.04, d=0.25$.

To examine the influence of trip familiarity/predictability on the return trip effect, participants also indicated the extent to which they recognized certain waypoints on the return trip that they had seen on the initial trip on a scale from 1 (none) to 9 (alot) $(M=5.32, \mathrm{SD}=2.15)$. A regression analysis showed that how much they recognized along the way (as a measure of familiarity) was unrelated to the return trip effect, $\beta=.15, t(67)=1.21, p=.23$; recognizing more waypoints during the return-trip did not influence the perception that the return trip took less time than had the initial trip.

To examine the effect of expectations on the return trip effect, participants indicated whether the initial trip took shorter or longer than they had expected on an 11-point scale from -5 (much shorter) to +5 (much longer). On average, participants indicated that the initial trip took longer than they had expected $(M=0.59, \mathrm{SD}=2.27$, which

\footnotetext{
${ }^{1}$ How long the trip took had no influence on any of our measures, all $\beta \mathrm{s}<.15, p \mathrm{~s}>.2$.
}

differs from 0$), t(68)=2.17, p=.03, d=0.26$. Furthermore, this violation of expectations predicted the return trip effect: The more travelers thought that the initial trip took longer than they had expected, the more they felt that the return trip took less time than the initial trip had, $\beta=-.27, \mathrm{t}(67)=$ $2.25, p=.02$.

\section{Study 2}

Study 2 attempted to replicate the findings of Study 1 using a different task. In Study 1, participants' familiarity with the return route, as measured by the number of waypoints recognized, did not influence the return trip effect. However, this measure might not have accurately or fully captured their familiarly with the return route. Therefore, the possible role of familiarity in the return trip effect was examined in Study 2 by having participants return either by the same or by a different, equidistant route.

\section{Method}

Ninety-three 1st-year students (67 females, $M_{\text {age }}=19$ years) at a get-to-know-each-other event at the start of the academic year traveled by bike from a base camp (where they had spent one night) to a nearby forest to play some games for about $2 \mathrm{~h}$. Participants traveled in small groups of 5-10 participants and followed someone who knew the way (who was not included in the sample). Participants were randomly assigned to travel along one of two equally long routes on the initial leg of the trip (route $1=9.23 \mathrm{~km}$, route $2=9.19 \mathrm{~km}$ ), both of which, in a pretest, took $35 \mathrm{~min}$. A separate group of participants (a control group) traveled the initial leg via route $1(n=10)$ or route $2(n=8)$. They were asked at the end of the initial trip how long it had felt to them in minutes. They confirmed that both routes felt equally long $\left(M_{\text {route1 }}=41.5 \mathrm{~min}, M_{\text {route2 }}=\right.$ $42.5 \mathrm{~min}), t(16)=0.24, p=.83, d=0.10$.

For the main group of participants, we manipulated whether they returned by the same route as that initially traveled $(n=32)$ or by the other one $(n=50){ }^{2}$ After participants arrived back at base camp, they filled out a questionnaire measuring their time perceptions of the initial and return trips. All estimates were given after both trips had been completed so that participants on each leg of the trip were unaware that they would be estimating duration (knowing that an estimation will be required can change time perception; Block \& Zakay, 1997).

\footnotetext{
${ }^{2}$ Eight participants were excluded from the analysis, since they got lost during the return trip. Three more were deleted because a multivariate outlier analysis indicated that their responses deviated strongly from the responses of the other participants.
} 


\section{Results}

We conducted a $2 \times 2$ mixed-model Type III ANOVA with same route versus different route as a between-subjects variable and time estimate (in minutes) of initial trip versus return trip as a within-subjects variable. Participants exhibited a clear return trip effect, estimating that the initial trip took longer $(44.3 \mathrm{~min})$ than the return trip $\operatorname{did}(36.9 \mathrm{~min}), F(1,80)=$ 19.02, $p<.001, \eta_{\mathrm{p}}{ }^{2}=.19$. Note that the estimates for how long the initial trip took $(M=44.3 \mathrm{~min})$ did not differ from the estimate of the control group $(M=41.9 \mathrm{~min})$, who made a time estimate directly after the initial trip, $t(98)=0.78, p=$ $.44, d=0.16$. Even though participants who completed the full experiment gave estimates for the initial leg after a long delay, their estimates did not differ from those of the control group, who estimated duration directly after completing the trip. As further evidence for the return trip effect, how long the return trip felt to participants $(M=36.9 \mathrm{~min})$ was shorter than the estimate the control group made for how long the initial trip felt $(M=41.9 \mathrm{~min}), t(98)=2.06, p=.04, d=0.42$.

Varying the return route allowed us to directly examine the role of familiarity in the return trip effect. First, there was an unexpected main effect of condition showing that participants who took a different route on the way back made longer estimates for both the initial trip and the return trip (42.3 min on average) than did participants who returned by the same route $(38.2 \mathrm{~min}), F(1,80)=5.34, p=.02, \eta_{\mathrm{p}}{ }^{2}=$ .06. Importantly, however, the magnitude of the return trip effect was not significantly different for participants who returned either by the same or by a different route, $F(1,80)=$ $1.77, p=.19, \eta_{\mathrm{p}}{ }^{2}=.02$. While a lack of familiarity might have caused participants who returned by novel routes to give longer estimates overall, familiarity with the route did not explain the return trip effect.

As in the previous experiment, participants indicated whether or not the initial trip took longer than they had expected on the scale from -5 (a lot shorter than expected) to +5 (a lot longer than expected). Participants thought that the initial trip took longer than expected $(M=1.46, \mathrm{SD}=$ 1.64, which differed from 0$), t(89)=8.19, p<.001, d=$ 0.89 . More important, this violation of expectations again predicted the return trip effect: The more participants thought that the initial trip took longer than expected, the shorter they felt the return trip took, as compared with the initial trip (as measured by the difference in minutes of the estimated duration of the initial and the return trips), $\beta=-.33, t(80)=3.12, p=.003$.

\section{Study 3}

In a final study, the return trip effect was tested in a more controlled setting. To do so, participants watched a video of someone traveling by bike from her home to a friend's house and back again at a later time. We made the video so that the initial and return trip were of exactly the same length, both in time and in distance traveled. Therefore, for example, different speeds of travel could not influence the time estimates (as found by Cohen \& Cooper, 1962; Cohen, Hansel, \& Sylvester, 1953). To further test the hypothesis that the return trip effect is caused by a violation of initial expectations, after which the return trip feels less bad in comparison, a condition was added where the initial expectations were manipulated. If, as indicated by participants in the previous studies, a feeling that the initial trip took much longer than expected contributes to the return trip effect, making participants expect an overly long initial trip should lessen or eliminate the return trip effect. Finally, order of estimates was manipulated to make sure that when the estimates were given could not account for the return trip effect.

\section{Method}

One hundred thirty-nine participants ( 94 females, $M_{\text {age }}=21$ years) took part in a series of studies of which ours was part. The basic setup was that participants were seated behind a computer and were told that they would see a video of a student who traveled by bike from her house to that of a friend. The video was shot from the viewpoint of the person riding the bike (the rider could not be seen). The bike ride took exactly $7 \mathrm{~min}$, during which a distance of $2.25 \mathrm{~km}$ was traveled. After this video had been seen, other studies followed for about $10 \mathrm{~min}$. Next, the participants again watched a video of the student riding a bike, but now described as returning from her friend's house to her home (with exactly the same time length). The main dependent variables were again how long participants felt the initial trip and the return trip took. Five conditions were created:

1. Basic return trip effect. After seeing the return trip, participants were asked to indicate how long they felt that the return trip had taken (on a sliding scale that could range between 1 and $20 \mathrm{~min}$ ). After answering this question, they indicated how long they had felt that the initial trip had lasted, on the same scale.

2. Question order control. This condition was exactly the same as the basic return trip effect condition, except that the order of the estimates was varied. Participants first indicated how long the initial trip had felt and then how long the return trip had felt.

3. Question timing control. This procedure was the same as that of the basic return trip effect condition, but participants indicated how long the initial trip felt directly after viewing the initial trip. After they saw the return trip, they indicated how long they felt the return trip had taken. 
4. Different return trip. The procedure was exactly the same as that of the basic return trip effect, but the video of the return trip showed a different (but equally long) route on the return trip.

5. Expectancy manipulation before initial trip. The procedure was exactly the same as that of the basic return trip effect, but before the participants saw the initial trip, they were told that they would first read what a previous participant had written about his experience after watching the video. They were presented with a handwritten statement, which was scanned in and presented on the screen. It first read the instruction to that other participant: "Please write down what your experience was (what you thought or felt) when you watched the video of the student riding her bike." It was answered with: "phewwww, that video took a lot longer than I expected."

\section{Results}

We conducted a mixed-model Type III ANOVA with time estimates of the initial and return trips as within-subjects variables and the five conditions described above as the between-subjects variable. Across conditions, a clear return trip effect existed. Participants felt that the initial trip took a lot longer $(M=9.12 \mathrm{~min}, S D=3.54)$ than the return-trip $\operatorname{did}(M=7.35, S D=2.59), F(1,134)=70.35, p<.001, \eta_{\mathrm{p}}{ }^{2}=$ .34 , even though both took exactly $7 \mathrm{~min}$. An interaction effect indicated that differences existed between conditions, $F(4,134)=2.97, p=.022, \eta_{\mathrm{p}}{ }^{2}=.08$ (see Table 1 for full results). In the three basic control conditions (where only the question order or timing was manipulated), a significant return trip effect existed. Note that an analysis of the difference between the estimates of the initial and the return trips showed that asking for a time estimate of the initial trip directly after that trip had been seen reduced the return trip effect, as compared with the basic return trip effect condition $(p=.061)$ and the question order control condition ( $p=$ $.042)$. The latter conditions did not differ $(p=.972)$. This demonstrates that the order in which questions about the time estimates of the initial or return trip are asked does not eliminate the return trip effect, although asking for a time estimate directly after the initial trip does seem to reduce it somewhat.

A conservative way of testing the return trip effect is to compare the time estimates of the participants who estimated the duration of the initial trip directly after seeing it (in the question timing control condition, $M=9.21 \mathrm{~min}$, $S D=3.99)$ with those of the participants who made an estimate of the return trip directly after seeing the return trip (in the basic return trip effect condition, $M=7.14$ $\min , S D=2.21)$. This between-subjects analysis also strongly confirms the existence of the return trip effect, $t$ $(54)=2.40, p=.020, d=0.64$. This shows that the return trip effect is not only a within-subjects phenomenon, and it rules out the possibility that the pattern exists because people might have a lay theory regarding a return trip that they wish to confirm.

Given that there was a return trip effect and question order did not appear to matter, we next examined the effect of familiarity with the return trip. One group of participants watched the rider travel back via a different (but equally long) route, while the remaining participants saw the rider return by the same initial route. As in the previous study, the return trip effect remained when participants returned by a different route: The different return trip group did not differ from the basic control ( $p=.667$ ), the question order control ( $p=.554)$, or the question timing control $(p=.147)$ group. Being familiar with the return trip is not necessary for the return trip effect to occur, nor does it seem to influence the strength of the effect.

Recall that in the previous two studies, the more participants felt that the initial trip took longer than expected, the stronger they experienced the return trip effect. Therefore, in the expectancy manipulation condition, participants were led to believe that the initial trip would take a long time so that there would not be a violation of expectations. If the return trip effect is due to a violation of initial expectations for a short trip, lengthening participants'

Table 1 Return trip effect per condition in Study 3

\begin{tabular}{|c|c|c|c|c|c|c|c|}
\hline & \multicolumn{2}{|c|}{ Initial Trip (minutes) } & \multicolumn{2}{|c|}{ Return Trip (minutes) } & \multicolumn{3}{|c|}{ Return Trip Effect } \\
\hline & $M$ & $(S D)$ & $M$ & $(S D)$ & Paired $t(28)$ & $p$ & $r^{2}$ \\
\hline Basic return trip effect & 9.54 & $(2.93)$ & 7.14 & $(2.21)$ & 5.01 & $<.001$ & .47 \\
\hline Question order control & 9.36 & $(4.02)$ & 6.86 & $(2.24)$ & 5.52 & $<.001$ & .52 \\
\hline Question timing control & 9.21 & $(3.99)$ & 8.07 & $(3.13)$ & 2.50 & .019 & .18 \\
\hline Different return trip & 9.39 & $(3.68)$ & 7.29 & $(2.58)$ & 4.54 & $<.001$ & .42 \\
\hline Expectancy manipulation before initial trip & 8.04 & $(2.94)$ & 7.37 & $(2.72)$ & 1.34 & .192 & .06 \\
\hline
\end{tabular}


expectations for the initial trip should lessen or eliminate the return trip effect. Indeed, in this condition, no return trip effect existed, since the estimates of how long the initial and return trips felt did not differ (see Table 1). Ironically, when a manipulation made participants expect a longer initial trip, they actually experienced the trip as taking less time, as compared with participants in the other conditions, as indicated by a planned contrast $t(134)=1.76, p=.08, d=$ 0.31 . This is further support for the idea that one of the causes of the return trip effect is that people are generally disappointed in the initial trip, after which the return trip seems relatively short again.

\section{Conclusion}

These studies demonstrate that there is a return trip effect; a pretest shows that people regularly experience the return trip as being shorter than the initial trip, and the effect was found on a bus trip (Study 1), a bicycle trip (Study 2), and while a video of someone else traveling by bike was watched (Study 3). The return trip effect is quite large: In Study 2, the return trip was felt to be $17 \%$ shorter in duration than the initial trip; in Study 3, it was felt to be $22 \%$ shorter (across the four conditions in which an effect was predicted).

The results indicate that the return trip effect is not due to an increase in familiarity, since the return trip effect also exists when people travel a different but equally long trip back. Instead, the return trip effect is likely due to a violation of expectations. Participants felt that the initial trip took longer than they had expected. In response, they likely lengthened their expectations for the return trip. In comparison with this longer expected duration, the return trip felt short. The greater the participants' expectations were violated on the initial trip, the more they experienced the return trip effect (Studies 1 and 2). In Study 3, where participants' expectations for the duration of the initial trip were increased via a manipulation, the return trip effect disappeared.

It is possible that other causes exist for the return trip effect and that it is a multidetermined phenomenon. The main goal of the present research was to test whether a return trip effect exists and to test two possible explanations. It provides a starting point for subsequent research that examines the role of other aspects, such as motivation, valence of the trip and destination, and the effect of learning on the return trip effect-what strengthens it and what the boundary conditions are.

Finding that a violation of expectations (at least partly) causes the return trip effect does allow us to make new predictions related to the return trip effect. One of our personal observations on the return trip effect is that it does not seem to occur for routes traveled frequently, such as commuting to work. It is likely that for these routes, the expectations become more accurate with repeated feedback (Roy, Mitten, \& Christenfeld, 2008), which attenuates the return trip effect.

More generally, the findings on the return trip effect could also help us predict people's time estimates on other repeated tasks. For example, we predict that people who watch a movie for a second time are likely to perceive the second viewing as taking less time (especially if the first viewing seemed overly long). Indeed, one of the authors noted a similar effect when reading a story to his children the second time. These findings on the return trip effect can thus help us make new predictions on how people experience the duration of tasks unrelated to traveling as well.

Acknowledgements The authors thank Leanne Braber and Terri Seuntjens for their help in conducting the studies and Veolia and OAD for providing the opportunity to contact their travelers in Study 1. Part of this research was made possible by a Rubicon grant (446-09-013) provided by the Netherlands Organization for Scientific Research (NWO).

Open Access This article is distributed under the terms of the Creative Commons Attribution Noncommercial License which permits any noncommercial use, distribution, and reproduction in any medium, provided the original author(s) and source are credited.

\section{References}

Avni-Babad, D., \& Ritov, I. (2003). Routine and the perception of time. Journal of Experimental Psychology: General, 132, 453550.

Block, R. A., \& Zakay, D. (1997). Prospective and retrospective duration judgments: A meta-analytic review. Psychonomic Bulletin \& Review, 4, 184-197.

Boltz, M. G. (1993). Time-estimation and expectancies. Memory \& Cognition, 21, 853-863.

Boltz, M. G. (1995). Effects of event structure on retrospective duration judgments. Perception \& Psychophysics, 57, 1080 1096.

Boltz, M. G. (1998). Task predictability and remembered duration. Perception \& Psychophysics, 60, 768-784.

Boltz, M. G., Kupperman, C., \& Dunne, J. (1998). The role of learning in remembered duration. Memory \& Cognition, 26, 903921.

Buehler, R., Griffin, D., \& Ross, M. (2002). Inside the planning fallacy: The causes and consequences of optimistic time predictions. In T. Gilovich, D. Griffin, \& D. Kahneman (Eds.), Heuristics and biases: The psychology of intuitive judgment (pp. 250-270). Cambridge: Cambridge University Press.

Burt, C. D. B., \& Kemp, S. (1991). Retrospective duration estimation of public events. Memory \& Cognition, 19, 252-262.

Cohen, J., \& Cooper, P. (1962). New phenomena in apparent duration, distance and speed. Nature, 196, 1233-1234. 
Cohen, J., Hansel, C. E. M., \& Sylvester, J. D. (1953). A new phenomenon in time judgment. Nature, 172, 901.

Hinds, P. J. (1999). The curse of expertise: The effects of expertise and debiasing methods on predictions of novice performance. Journal of Experimental Psychology: Applied, 5, 205-221.

Kahneman, D., \& Tversky, A. (1979). Intuitive predictions: Biases and corrective procedures. TIMS Studies in Management Sciences, $12,313-327$.

Poynter, D. W. (1989). Judging the duration of time intervals: A process of remembering segments of experience. In I. Levin \& D. Zakay (Eds.), Time and human cognition (pp. 305-331). Amsterdam: North-Holland.
Roy, M. M., \& Christenfeld, N. J. S. (2007). Bias in memory predicts bias in estimation of future task duration. Memory \& Cognition, $35,557-564$.

Roy, M. M., Christenfeld, N. J. S., \& McKenzie, C. R. M. (2005). Underestimating the duration of future events: Memory incorrectly used or memory bias? Psychological Bulletin, 131, 738756.

Roy, M. M., Mitten, T. S., \& Christenfeld, N. J. S. (2008). Correcting memory improves accuracy of predicted duration. Journal of Experimental Psychology: Applied, 14, 266-275.

Wallace, M., \& Rabin, A. I. (1960). Temporal experience. Psychological Bulletin, 57, 213-237. 